\title{
Radiation-Associated Small Cell Neuroendocrine Carcinoma of the Thyroid: A Case Report with Molecular Analyses
}

\author{
Zhanna Mussazhanova, ${ }^{1, *}$ Shiro Miura, ${ }^{2, *}$ Boban Stanojevic, ${ }^{3,4}$ Tatiana Rougounovitch, ${ }^{3}$ \\ Vladimir Saenko, ${ }^{3}$ Toshio Shiraishi, ${ }^{5}$ Tomomi Kurashige, ${ }^{2,6}$ Kazuko Shichijo, ${ }^{1}$ Kenichi Kaneko, ${ }^{7}$ \\ Haruo Takahashi, ${ }^{7}$ Masahiro Ito, ${ }^{8}$ and Masahiro Nakashima ${ }^{1,2}$
}

Background: Neuroendocrine tumor (NET) of the thyroid other than medullary carcinoma is extremely rare. We describe here a case of calcitonin-negative small cell neuroendocrine carcinoma (SCNEC), which occurred in a thyroid gland that had previously been irradiated at high dose (60Gy) for pharyngeal cancer, with molecular analyses for follicular cell origin.

Patient Findings: The tumor cells were small with fine chromatin, inconspicuous nucleoli, and inapparent cytoplasm, and showed neuroendocrine architectures such as palisading, rosettes, and trabeculae. Mitotic figures were numerous exceeding 10 mitoses per 10 high-power fields. The tumor cells invaded into several vessels and metastasized to regional lymph nodes. Immunohistochemically, the tumor cells were strongly positive for neuroendocrine markers and thyroglobulin (Tg), a marker of thyroid follicular cells but negative for calcitonin and carcinoembryonic antigen (CEA). Expression of Tg and thyrotropin receptor (TSHR) were confirmed by quantitative real-time polymerase chain reaction (RT-PCR). Ki-67 labeling index was more than $70 \%$ in the tumor cells. Taken together, the tumor was diagnosed as SCNEC of the thyroid. Genetic analyses also revealed microsatellite abnormalities of the phosphatase and tensin homolog (PTEN) gene, suggesting that functional loss of PTEN contributes to carcinogenesis. Conclusions: This is the first report describing a SCNEC of the thyroid with molecular analyses that provide evidence for a follicular epithelial origin.

\section{Introduction}

$\mathbf{T}$ HYROID CANCER RISK after exposure to ionizing radiation is of public concern. Papillary thyroid carcinoma (PTC) is well known as the principal thyroid cancer cell type linked to radiation, especially after childhood exposure (1). The histological type of thyroid cancer associated with therapeutic external radiation exposure is most commonly PTC (2). Anaplastic transformation of PTC is also rarely induced by internal radiation with ${ }^{131} \mathrm{I}$ after resection surgery for a primary tumor (3). We describe here a case of calcitonin-negative small cell neuroendocrine carcinoma (SCNEC) that occurred in a thyroid gland that had previously been irradiated at a high dose for pharyngeal cancer.

Neuroendocrine tumor (NET) of the thyroid other than medullary thyroid carcinoma (MTC), which is calcitonin positive, is extremely rare, and only one case of calcitoninnegative NET of the thyroid has previously been reported (4). That case was not associated with any history of radiation exposure and was histologically of the well-differentiated type, in which absence of mitotic activity, vascular invasion, and necrosis were noted. This is the first report describing a high-grade NET of the thyroid with molecular analyses with evidence of a thyroid follicular cell origin, and with alterations of the phosphatase and tensin homolog (PTEN) tumor suppressor gene.

\section{Case Presentation}

A 64-year-old Japanese male noticed a cervical mass. He was an ex-smoker of 30 cigarettes per day for 20 years. His family history did not include any endocrine disorders or any cancer syndromes. However, the patient had a past history of

Departments of ${ }^{1}$ Tumor and Diagnostic Pathology, ${ }^{3}$ Radiation Medical Sciences, and ${ }^{6}$ Molecular Medicine, ${ }^{2}$ Tissue and Histopathology Section, Division of Scientific Data Registry, Atomic Bomb Disease Institute; ${ }^{5}$ School of Medicine; Nagasaki University, Nagasaki, Japan

${ }^{4}$ Laboratory for Radiobiology and Molecular Genetics, Vinca Institute of Nuclear Sciences, Belgrade, Serbia.

${ }^{7}$ Department of Otolaryngology-Head and Neck Surgery, Nagasaki University Hospital, Nagasaki, Japan.

${ }^{8}$ Department of Pathology, National Hospital Organization Nagasaki Medical Center, Omura, Japan.

*Z.M. and S.M. are jointly considered as first authors. 
three primary cancers other than thyroid gland including esophageal cancer 18 years ago, squamous cell carcinoma of the lower pharynx 10 years ago, and moderately differentiated adenocarcinoma of the stomach 3 years ago. Surgical resections were performed for the esophageal and gastric cancers and no recurrence was evident so far. For the pharyngeal cancer, the patient underwent total resection of both the lower pharynx and larynx combined with left hemithyroidectomy and reconstruction by jejunal interposition. After the latter resection, he also received $60 \mathrm{~Gy}$ of external irradiation to the whole neck. One year before noticing his cervical mass, squamous cell carcinoma had recurred at his upper pharynx, which was treated by endoscopic mucosal resection, followed by $35 \mathrm{~Gy}$ of local external irradiation and chemotherapy with 5FU and CDDP.

Examination of the cervical mass by magnetic resonance imaging (MRI) disclosed a right thyroid mass and multiple swollen lymph nodes in the paratracheal and superior mediastinum, suggesting thyroid cancer (Fig. 1). Fine-needle aspiration was carried out, which showed malignant cells suspicious for undifferentiated carcinoma. Preoperatively, he was found to be profoundly hypothyroid: thyrotropin (TSH) $404.1 \mu \mathrm{IU} / \mathrm{mL}$, free thyroxine $\left(\mathrm{FT}_{4}\right) 0.13 \mathrm{ng} / \mathrm{mL}$, free triiodothyronine $\left(\mathrm{FT}_{3}\right) 0.30 \mathrm{pg} / \mathrm{mL}$, and thyroglobulin (Tg) $215.9 \mathrm{ng} /$ $\mathrm{mL}$. The measurements of calcitonin and parathyroid hormone were not preoperatively performed. He subsequently underwent right thyroidectomy with dissection of the lymph nodes to remove the thyroid mass, which measured $5.4 \mathrm{~cm} \times$ $2.7 \mathrm{~cm} \times 1.9 \mathrm{~cm}$, that occupied the right lobe of the thyroid gland (Fig. 1). He had no clinical evidence of tumor recurrence at the 1-year follow-up examination.

\section{Pathologic Findings}

The resected right thyroid gland was replaced by tumor cells and demonstrated few remaining nontumorous thyroid follicles. Tumor showed nested/nodular growth pattern with occasional foci of comedo-like necrosis, which was separated by fibrovascular stroma (Fig. 2). Neuroendocrine architectures, such as palisading, rosettes, and trabeculae, were clearly observed in the tumor nests (Fig. 2). The tumor cells were small in size ( $<3$ lymphocytes) and oval to polygonal in shape with fine chromatin, inconspicuous nucleoli, and inapparent cytoplasms (Fig. 2). Mitotic figures were numerous exceeding 10 mitoses per 10 high-power fields (Fig. 2). Tumor cells invaded into several vessels and metastasized to regional lymph nodes. The pathologic tumor stage was pT3N1bM0.

\section{Immunhistochemical Profiles}

Immunohistochemistry was performed on formalin-fixed, paraffin-embedded (FFPE) tissue sections from the resected thyroid tumor. Antibodies used in this study are shown in Supplementary Table S1 (Supplementary Data are available online at www.liebertpub.com/thy). The immunohistochemical results are detailed in Table 1 and depicted in Figure 3, respectively. It was observed that the tumor cells were positive for neuroendocrine markers, such as synaptophysin and CD56, and weakly positive for chromogranin A. Further, the staining was strongly positive for thyroglobulin but negative for thyroid
FIG. 1. Magnetic resonance imaging $(\mathbf{A}, \mathbf{B})$ and macroscopic view $(\mathbf{C}$, D) of the right thyroid tumor. The patient had received postsurgical treatment for pharyngeal cancer, including total resection of both the lower pharynx and larynx combined with left hemithyroidectomy and reconstruction by jejunal interposition.
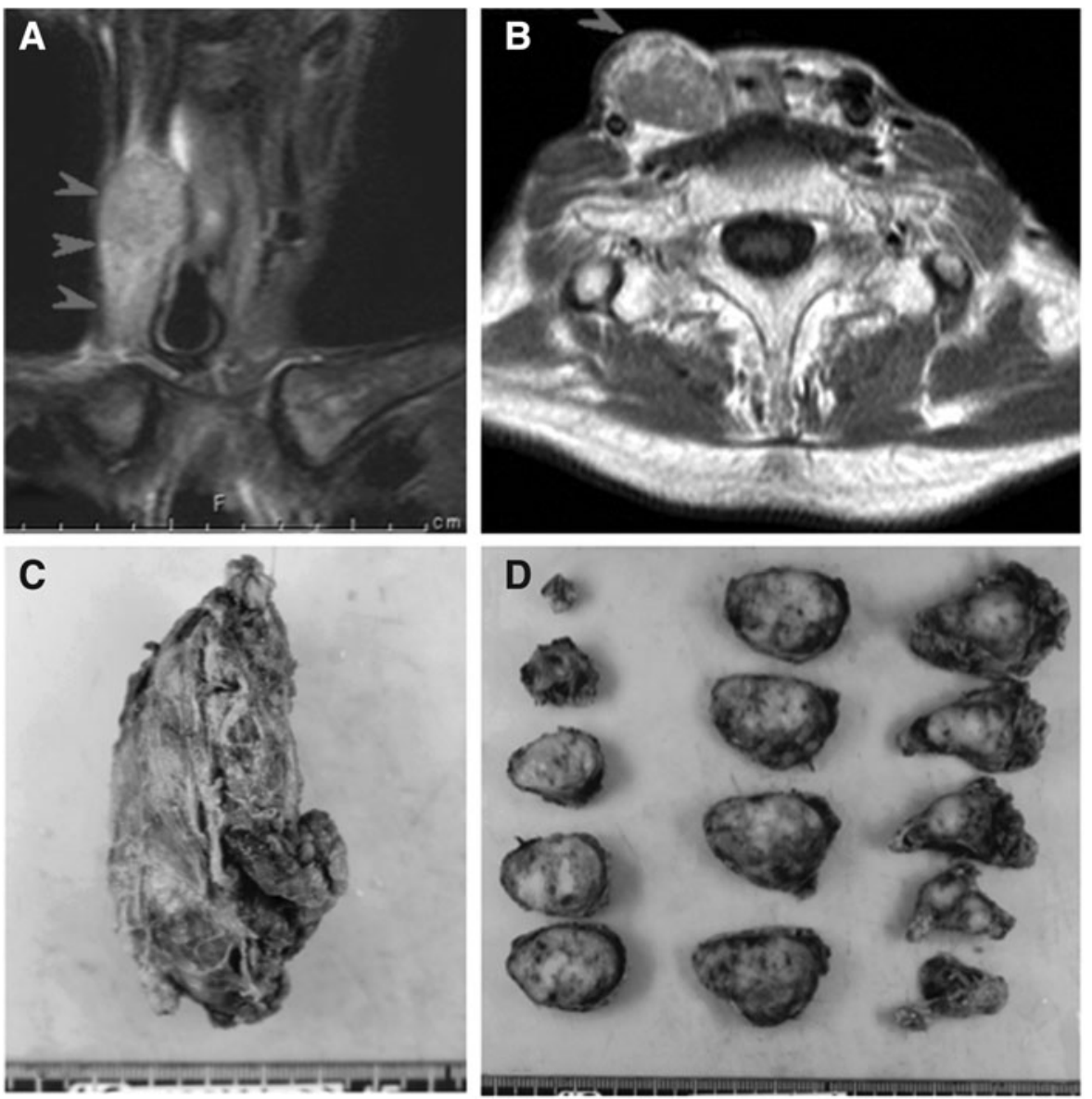

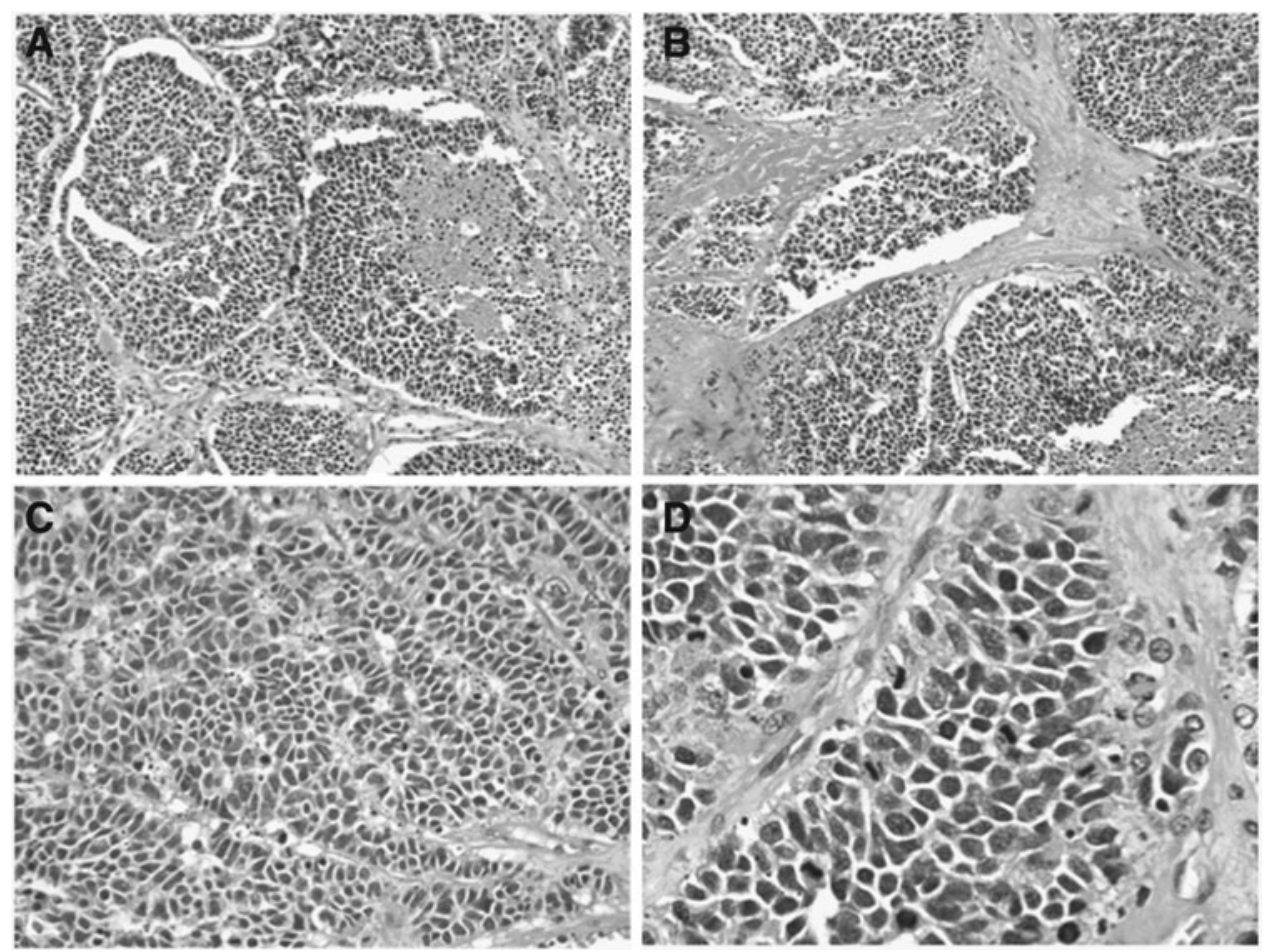

FIG. 2. Histology of the present thyroid tumor. The tumor showed nested/ nodular growth pattern with occasional foci of comedo-like necrosis (A, original magnification $\times 100$ ) and occasional invasion into vessels (B, $\times 100)$. Neuroendocrine morphology, such as palisading, rosettes, and trabeculae, was apparently observed in the tumor nests, which were separated by delicate fibrovascular stroma $(C, \times 200)$. The tumor cells were small in size and oval to polygonal in shape with fine chromatin, inconspicuous nucleoli, and inapparent cytoplasm $(\mathrm{D}, \times 400)$. Numerous mitotic figures were observed (D).

transcription factor-1 (TTF-1), both of which are markers of thyroid follicular cell. Immunoreactivity for calcitonin and carcinoembryonic antigen (CEA) was not observed in the tumor cells. The tumor was also weakly positive for p53, and Ki-67 labeling index was more than $70 \%$ in the tumor cells (Supplementary Fig. S1).

\section{Molecular Analyses}

\section{Expression of TTF-1, Tg, and TSH receptor by quantitative real-time $R T$-PCR}

Total RNA was extracted from FFPE tissues of the present case and two cases of PTC as well as their corresponding normal thyroid tissues, which acted as positive controls, using the High

Table 1. Immunohistochemical Results in the Present Case

\begin{tabular}{lc}
\hline Antibody & Results \\
\hline Synaptophysin & ++ \\
CD56 & ++ \\
Chromogranin A & $+/-$ \\
Thyroglobulin & ++ \\
Calcitonin & - \\
CEA & - \\
TTF-1 & - \\
AE1/AE3 & + \\
Cytokeratin 7 & - \\
Cytokeratin 20 & - \\
Vimentin & - \\
p53 & $+/-$ \\
Ki67 LI & $70 \%$ \\
\hline
\end{tabular}

${ }^{\mathrm{a}}++$, positive cells $>60 \% ;+, 30 \% \sim 60 \% ;+/-, 5 \sim 30 \% ;-,<5 \%$.

CEA, carcinoembryonic antigen; TTF-1, thyroid transcription factor-1; LI, labeling index.
Pure RNA Paraffin Kit (Roche, Mannheim, Germany) according to the manufacturer's protocol. The cDNA was generated with the SuperScript III First Strand Synthesis SuperMix (Invitrogen, Carlsbad, CA) and analyzed by quantitative real-time polymerase chain reaction (RT-PCR) using Sybr Premix ExTaq qPCR primer assays (Takara Bio, Shiga, Japan) and the Thermal Cycler Dice Real Time multicolor PCR detection system (Takara, Shizuoka, Japan). The primers used in this study are summarized in Supplementary Table S2. Amplicons were designed to span introns to exclude genomic DNA contamination. PCR products were separated on $1 \%$ agarose gels and visualized by ethidium bromide staining (Fig. 4A). These assays demonstrated the expressions of both TSH receptor and Tg, but not of TTF-1, in the present case at the transcript level. All three genes were expressed by the two cases of PTC and/or their corresponding nontumor part of thyroid tissues.

\section{Analysis for RET/PTC rearrangements and $\mathrm{BRAF}^{\mathrm{V} 600 \mathrm{E}}$ mutations}

Expression of RET/PTC1 and RET/PTC3 genes were assessed by RT-PCR as described in a previous report (5). Neither RET/PTC1 nor RET/PTC3 was demonstrated in the present case. Furthermore, tumor DNA was amplified to generate products covering the common mutational hotspots of $B R A F$, including a portion of exon 15 and and sequenced on an ABI PRISM 3130 automated capillary DNA Sequencer (Applied Biosystems) using the BigDye Terminator Cycle Sequencing Ready Reaction Kit version 3.1 (Applied Biosystems). No BRAF mutations were detected in the present case.

\section{Loss of heterozygosity analysis of the phosphatase and PTEN tumor suppressor gene}

Using a Tissue Mini DNA Purification Kit (Epicentre Biotechnologies), genomic DNA was extracted from FFPE tissues 

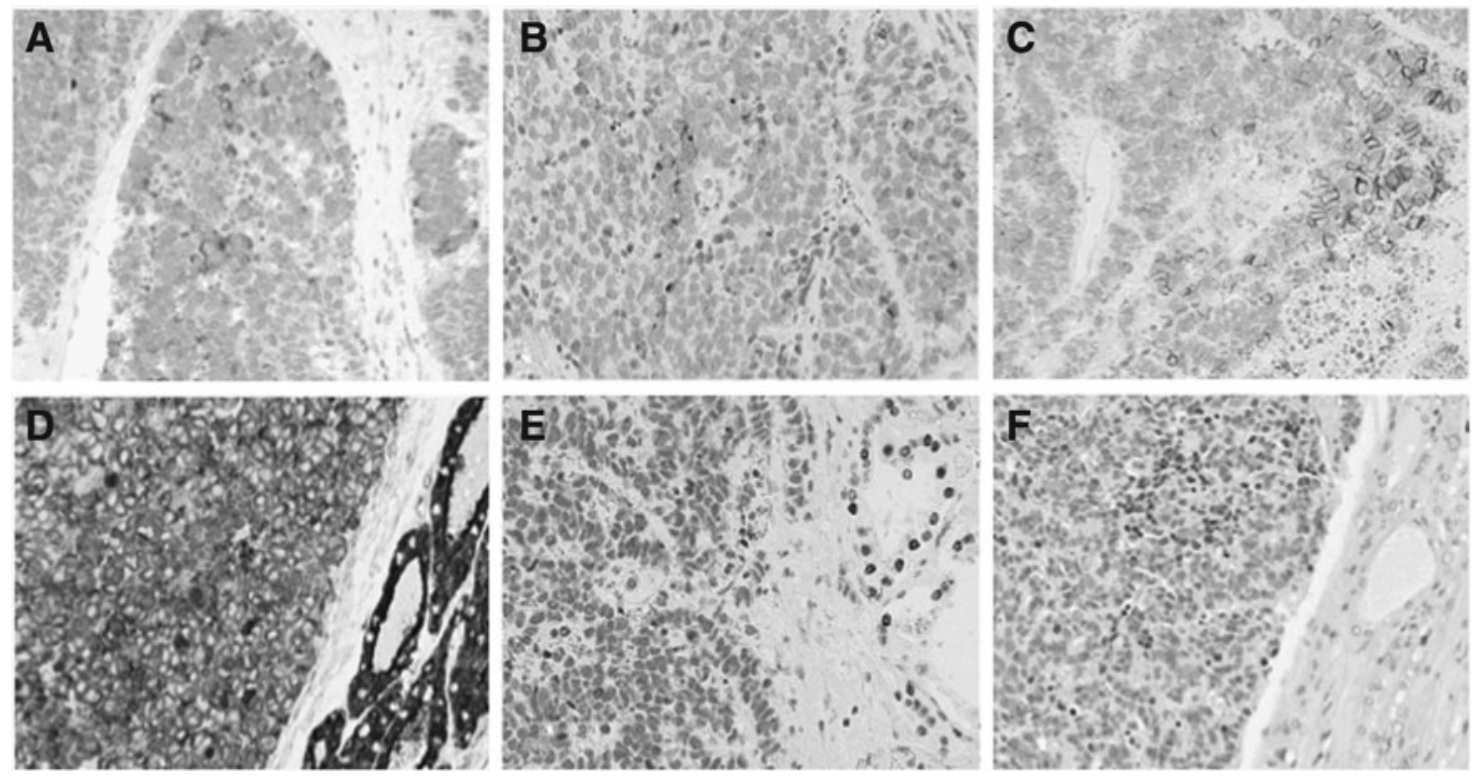

FIG. 3. Immunohistochemistry for synaptophysin (A), chromogranin A (B), CD54 (C), thyroglobulin (D), thyroid transcription factor $(\mathrm{TTF})-1$ (E), and cytokeratin 7 (F) in the present case (original magnification: $\times 200$ ).

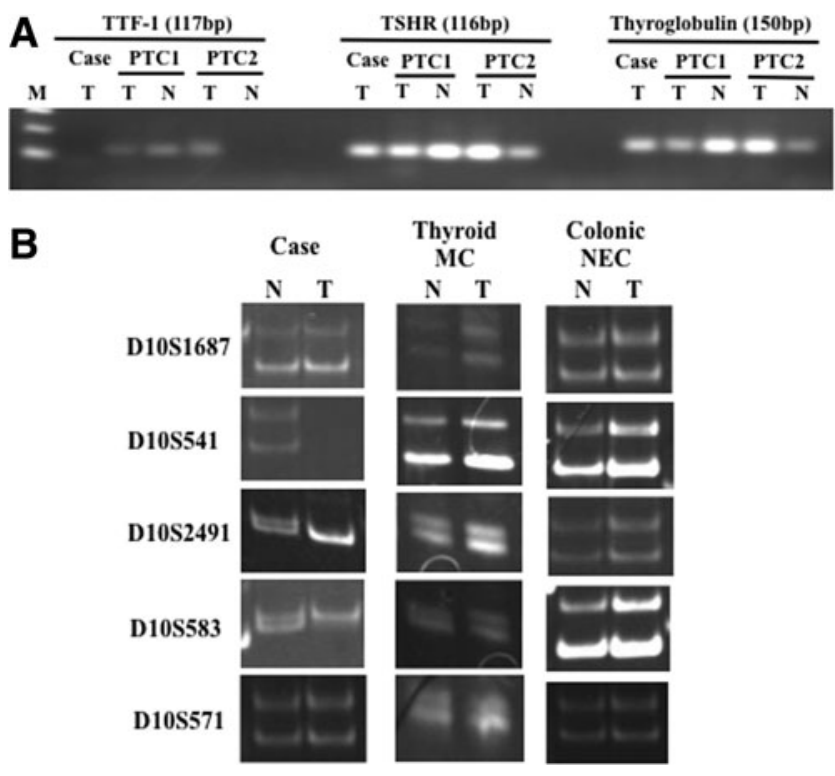

FIG. 4. (A) Reverse transcriptse polymerase chain reaction (RT-PCR) analyses for thyroid transcription factor (TTF)-1, thyroid stimulating hormone (TSH) receptor, and thyroglobulin in the present case with two cases of papillary thyroid carcinomas as control subjects (PTC1 and PTC2) (T, tumor; N, its corresponding normal thyroid). (B) Loss of heterozygosity $(\mathrm{LOH})$ analysis of the phosphatase and tensin homolog (PTEN) gene. The present case showed microsatellite abnormalities in three of the five markers, including a biallelic loss at D10S541 and two monoallelic losses at D10S2491 and D10S583, while neither thyroid medullary carcinoma (MC) nor colonic neuroendocrine carcinoma (NEC) showed any microsatellite abnormalities in these markers. of both the tumor and its corresponding lymph node without metastasis from the present case as well as a case of MTC and a case of colonic NEC, which were used for loss of heterozygosity $(\mathrm{LOH})$ analysis by PCR. PCR reactions were routinely performed in a final volume of $25 \mu \mathrm{L}$ containing $10 \mathrm{ng}$ of sample DNA with the hot start ExTaq polymerase (Takara). Five microsatellite markers were used to determine $\mathrm{LOH}$ in the $10 \mathrm{q} 23$ region and its flanking polymorphic genetic markers as described in a previous report (6). PCR was performed under the following conditions: initial denaturation at $95^{\circ} \mathrm{C}$ for 5 minutes followed by 37 cycles of amplification $\left(94^{\circ} \mathrm{C}\right.$ for 30 seconds, $56^{\circ} \mathrm{C}$ for 30 seconds, and $72^{\circ} \mathrm{C}$ for 30 seconds), and a final extension at $72^{\circ} \mathrm{C}$ for 10 minutes, followed by a $4^{\circ} \mathrm{C}$ cooling step. Aliquots of the PCR products were electrophoresed on $12 \%$ denaturing polyacrylamide gels at $50 \mathrm{~V}$ for 24 hours. After electrophoresis, the allelic band intensity was detected using a commercially available ethidium bromide solution, and was captured and analyzed using a BioDoc-It Imaging System (UVP, Inc., Upland, CA). $\mathrm{LOH}$ was scored when the intensity of one allele was absent or at least $75 \%$ reduced in the tumor alleles compared to the corresponding wild-type alleles in the normal tissue.

The present case showed microsatellite abnormalities in three of the five markers, including a biallelic loss at D10S541 and two monoallelic losses (LOH) at D10S2491 and D10S583, while neither thyroid medullary carcinoma nor colonic neuroendocrine carcinoma showed any microsatellite abnormalities in the five markers (Fig. 4B).

\section{Discussion}

This article describes a case of SCNEC of the thyroid that occurred in a patient who had a past history of radiation therapy for hypopharyngeal cancer. In the thyroid gland, although MTC is well known as a NET arising from the calcitonin-producing parafollicular cells (C-cells) that accounts for up to $10 \%$ of all thyroid cancers, only one case of calcitonin-negative 
nonmedullary NET has previously been reported, which expressed $\mathrm{Tg}$, synaptophysin, and chromogranin A, but not calcitonin by immunostaining, indicating a follicular cell origin (4). In the present case, the expression of three markers of neuroendocrine differentiation, but not of calcitonin nor CEA, were demonstrated. We also confirmed the expression of thyrotropin receptor (TSHR) and Tg at the transcription level, providing further evidence for a follicular cell origin of this tumor.

The expression of TTF- 1 was not detected in the present case at both mRNA and protein levels. TTF-1 expression is highly restricted to epithelial tumors arising in the thyroid and lung. Among pulmonary NETs, it has been documented that TTF- 1 expression is found in $35-50 \%$ of typical carcinoids, $100 \%$ of atypical carcinoids, $50 \%$ to $75 \%$ of large cell neuroendocrine carcinomas, and $81 \%$ to $95 \%$ of small cell carcinomas (7-9). Among thyroid NETs, MTCs seem to consistently express TTF-1 $(7,10)$, which is plausible because this protein is expressed in C-cells $(11,12)$. TTF-1 is a homeodomaincontaining transcriptional factor that binds to and activates the promoters of thyroid-specific genes including TSHR, $\mathrm{Tg}$, and thyroid peroxidase genes in follicular cells (13). Therefore, during carcinogenesis of SCNEC of the thyroid, the TTF-1 gene may be truncated, and the expression of some thyroidspecific genes, such as TSHR and Tg, may be regulated in a TTF-1 independent manner.

NETs may arise in most organs of the body and share many common pathologic features. The 2004 World Health Organization (WHO) classification recognizes four major types of lung NETs: low grade/typical carcinoid, intermediate grade/ atypical carcinoid, high grade/large cell neuroendocrine carcinoma, and small cell lung cancer (14). More recently, according to the $2010 \mathrm{WHO}$ classification scheme, gastroenteropancreatic (GEP)-NETs are separated into welldifferentiated NETs and poorly differentiated NECs of the small or large cell type (15). They are also divided according to a grading system, which is based on the Ki67 proliferation index or mitotic count. According to these criteria, the present case is a high-grade (G3) NEC of small cell type. To the best of our knowledge, this is the first report of SCNEC of the thyroid in the English literature. Because the patient received external radiation therapy to the whole neck for hypopharyngeal cancer 10 years prior to the diagnosis of thyroid cancer, a radiation etiology is suspected for this tumor. Although previous reports on postradiation small cell carcinoma are extremely rare, a case of secondary SCNEC of the cervix after radiotherapy for cervical squamous cell carcinoma has been documented (16). Radiation is a well-recognized risk factor in thyroid carcinogenesis, and it is typically associated with PTC. Therapy-related high-dose radiation might be able to induce rare types of thyroid cancer including SCNEC.

$P T E N$ is a tumor suppressor gene that has been found to be somatically deleted, mutated, and/or silenced in various sporadically occurring cancers such as glioblastoma, malignant melanoma, as well as thyroid, breast, endometrial, and ovarian carcinomas (17-23). Functional inactivation of the PTEN gene may occur through deletion, $\mathrm{LOH}$, and other mutations (24). In thyroid tumors, transcriptional silencing of PTEN has been shown to be significantly associated with the anaplastic subtype, suggesting that PTEN is involved in the carcinogenesis of highly malignant or late-stage thyroid cancers (25). Although several studies suggest that aberrant methylation of the PTEN promoter is an epigenetic mecha- nism in inactivating this gene in thyroid tumors (26-29), $\mathrm{LOH}$ of PTEN seems to be a common genetic event in SCNEC of the lung and gastrointestinal tract (30). In our analysis, microsatellite abnormalities of the PTEN gene, including a billelic and two monoallelic losses, were found in the present case but in neither MTC nor colonic NEC. Thus, inactivation of the PTEN gene is suggested to be involved in the carcinogenesis of thyroid SCNEC, similarly to anaplastic thyroid cancers and SCNECs found in other organs.

In summary, we describe a case of SCNEC of the thyroid, which occurred in a patient who had received therapy-related high dose irradiation. The findings suggest that the tumor was of follicular origin. To the best of our knowledge, this is the first report of calcitonin-negative high-grade NEC of the thyroid.

\section{Acknowledgments}

This work was supported in part through Nagasaki University Global Center of Excellence (COE) program "Global Strategic Center for Radiation Health Risk Control" and by Grant-in-Aid for Scientific Research from the Japanese Ministry of Education, Science, Sports and Culture (No. 18590334).

\section{Author Disclosure Statement}

The authors of this manuscript have no competing financial interests. They have no commercial associations that might create a conflict of interest in connection with the submitted manuscript.

\section{References}

1. Ron E, Schneider AB 2006 Thyroid cancer. In: Schottenfeld D, Fraumeni JF Jr (Eds) Cancer Epidemiology and Prevention. Oxford University Press, New York, pp 975-994.

2. Seaberg RM, Eski S, Freeman JL 2009 Influence of previous radiation exposure on pathologic features and clinical outcome in patients with thyroid cancer. Arch Otolaryngol Head Neck Surg 135:355-359.

3. Sera N, Ashizawa K, Ando T, Ide A, Abe Y, Usa T, Tominaga T, Ejima E, Hayashi T, Shimokawa I, Eguchi K 2000 Anaplastic changes associated with p53 gene mutation in differentiated thyroid carcinoma after insufficient radioactive iodine (131I) therapy. Thyroid 10:975-979.

4. Chernyavsky VS, Farghani S, Davidov T, Ma L, Barnard N, Amorosa LF, Trooskin SZ 2011 Calcitonin-negative neuroendocrine tumor of the thyroid: a distinct clinical entity. Thyroid 21:193-196.

5. Nakashima M, Takamura N, Namba H, Saenko V, Meirmanov S, Matsumoto N, Hayashi T, Maeda S, Sekine I 2007 RET oncogene amplification in thyroid cancer: correlations with radiation-associated and high-grade malignancy. Hum Pathol 38:621-628.

6. Garcia JM, Silva JM, Dominguez G, Gonzalez R, Navarro A, Carretero L, Provencio M, España P, Bonilla F 1999 Allelic loss of the PTEN region (10q23) in breast carcinomas of poor pathophenotype. Breast Cancer Res Treat 57:237-243.

7. Kaufmann O, Dietel M 2000 Expression of thyroid transcription factor-1 in pulmonary and extrapulmonary small cell carcinomas and other neuroendocrine carcinomas of various primary sites. Histopathology 36:415-420.

8. Cheuk W, Kwan MY, Suster S, Chan JK 2001 Immunostaining for thyroid transcription factor 1 and cytokeratin 20 aids the distinction of small cell carcinoma from 
Merkel cell carcinoma, but not pulmonary from extrapulmonary small cell carcinomas. Arch Pathol Lab Med 125:228-231.

9. Folpe AL, Gown AM, Lamps LW, Garcia R, Dail DH, Zarbo RJ, Schmidt RA 1999 Thyroid transcription factor-1: immunohistochemical evaluation in pulmonary neuroendocrine tumors. Mod Pathol 12:5-8.

10. Agoff SN, Lamps LW, Philip AT, Amin MB, Schmidt RA, True LD, Folpe AL 2000 Thyroid transcription factor-1 is expressed in extrapulmonary small cell carcinomas but not in other extrapulmonary neuroendocrine tumors. Mod Pathol 13:238-242.

11. Katoh R, Miyagi E, Nakamura N, Li X, Suzuki K, Kakudo K, Kobayashi M, Kawaoi A 2000 Expression of thyroid transcription factor-1 (TTF-1) in human C cells and medullary thyroid carcinomas. Hum Pathol 31:386-393.

12. Damante G, Tell G, Di Lauro R 2001 A unique combination of transcription factors controls differentiation of thyroid cells. Prog Nucleic Acid Res Mol Biol 66:307-506.

13. Yamada H, Takano T, Matsuzuka F, Watanabe M, Miyauchi A, Iwatani Y 2011 Transcriptional activity of the 5'-flanking region of the thyroid transcription factor- 1 gene in human thyroid cell lines. Genet Mol Biol 34:6-10.

14. Travis WD, Brambilla E, Muller-Hermelink HK, Harris CC 2004 Pathology and Genetics of Tumours of the Lung, Pleura, Thymus and Heart, World Health Organization Classification of Tumours, vol. 10. IARC Press, Lyon, France.

15. Rindi G, Arnold R, Bosman FT, et al 2010 Nomenclature and classification of neuroendocrine neoplasms of the digestive system. In: Bosman FT, Carneiro F, Hruban RH, Theise ND (Eds) WHO classification of tumours in the digestive system, 4th edition. IARC Press, Lyon, France, pp 13-14.

16. Gressner O, Sauerbruch T 2007 Secondary small cell neuroendocrine carcinoma of the cervix after radiotherapy for cervical squamous cell carcinoma. Int J Gynaecol Obstet 99:138.

17. Fan X, Aalto Y, Sanko SG, Knuutila S, Klatzmann D, Castresana JS 2002 Genetic profile, PTEN mutation and therapeutic role of PTEN in glioblastomas. Int J Oncol 21:1141-1150.

18. Deichmann M, Thome M, Benner A, Egner U, Hartschuh W, Näher H 2002 PTEN/MMAC1 expression in melanoma resection specimens. Br J Cancer 87:1431-1436.

19. Halachmi N, Halachmi S, Evron E, Cairns P, Okami K, Saji M, Westra WH, Zeiger MA, Jen J, Sidransky D 1998 Somatic mutations of the PTEN tumor suppressor gene in sporadic follicular thyroid tumors. Genes Chromosomes Cancer 23:239-243.

20. Bose S, Wang SI, Terry MB, Hibshoosh H, Parsons R 1998 Allelic loss of chromosome 10q23 is associated with tumor progression in breast carcinomas. Oncogene 17:123-127.
21. Martini M, Ciccarone M, Garganese G 2002 Possible involvement of hMLH1, P16 (ink4A) and PTEN in the malignant transformation of endometriosis. Int J Cancer 102: 398-406.

22. Risinger JI, Hayes AK, Berchuck A, Barrett JC 1997 PTEN/ MMAC1 mutations in endometrial cancers. Cancer Res 57:4736-4738.

23. Fujii $H$, Matsumoto $T$, Yoshida M, Furugen $Y$, Takagaki $T$, Iwabuchi K, Nakata Y, Takagi Y, Moriya T, Ohtsuji N, Ohtsuji M, Hirose S, Shirai T 2002 Genetics of synchronous uterine and ovarian endometrioid carcinoma: combined analyses of loss of heterozygosity, PTEN mutation and microsatellite instability. Hum Pathol 33:421-428.

24. Mutter GL 2001 Pten, a protean tumor suppressor. Am J Pathol 158:1895-1898.

25. Frisk T, Foukakis T, Dwight T, Lundberg J, Höög A, Wallin G, Eng C, Zedenius J, Larsson C 2002 Silencing of the PTEN tumor-suppressor gene in anaplastic thyroid cancer. Genes Chromosomes Cancer 35:74-80.

26. Alvarez-Nuñez F, Bussaglia E, Mauricio D, Ybarra J, Vilar M, Lerma E, de Leiva A, Matias-Guiu X; Thyroid Neoplasia Study Group 2006 PTEN promoter methylation in sporadic thyroid carcinomas. Thyroid 16:17-23.

27. Schagdarsurengin U, Gimm O, Dralle H, Hoang-Vu C, Dammann R 2006 CpG island methylation of tumor-related promoters occurs preferentially in undifferentiated carcinoma. Thyroid 16:633-642.

28. Xing M 2007 Gene methylation in thyroid tumorigenesis. Endocrinology 148: 948-953.

29. Hou P, Ji M, Xing M 2008 Association of PTEN gene methylation with genetic alterations in the phosphatidylinositol 3-kinase/AKT signaling pathway in thyroid tumors. Cancer 113:2440-2447.

30. Dacic S, Finkelstein SD, Baksh FK, Swalsky PA, Barnes LE, Yousem SA 2002 Small-cell neuroendocrine carcinoma displays unique profiles of tumor-suppressor gene loss in relationship to the primary site of formation. Hum Pathol 33:927-932.

Address correspondence to: Masahiro Nakashima, MD, PhD Department of Tumor and Diagnostic Pathology Atomic Bomb Disease Institute Nagasaki University 1-12-4 Sakamoto Nagasaki 852-8523 Japan

E-mail: moemoe@nagasaki-u.ac.jp 